\title{
SEISMIC BEHAVIOUR OF CONCRETE-FILLED STEEL TUBE FRAMES WITH EXTERNAL COMPOSITE WALL PANELS
}

\author{
Shi-Yi Wang ${ }^{1}$, An-Ying Chen ${ }^{1,}{ }^{*}$ and Hai-Ying Wan ${ }^{2}$ \\ ${ }^{1}$ School of Civil Engineering, Hefei University of Technology, Hefei, China \\ ${ }^{2}$ Anhui Collaborative Innovation Center for Advanced Steel Structure Technology and Industrialization, Hefei 230009, China \\ *(Corresponding author: E-mail: anyingchen@hfut.edu.cn)
}

\section{A B S T R A C T}

This study investigated the seismic performance of concrete-filled steel tube frames with external wall panels via experimental research, numerical and theoretical analysis. Pseudo-static tests were first performed on five concrete-filled steel tube frame specimens. The failure mode, hysteretic performance, stiffness degradation, strength degradation, ductility coefficient, and energy dissipation capacity in the essential components of the structural system were analysed. Besides, finite element analysis was then used to simulate the seismic performance of the specimen, and the predicted results were compared with the test results. A parametric analysis was then conducted to study the influence of the strength of the materials and the relative size of the wall openings on the structural system of the specimens. Finally, the numerical and experimental results were compared. The following results were obtained based on the observed failure modes of the specimens: (1) each specimen exhibited good seismic performance and safety reliability, (2) external wall panels improved the elastic stiffness and ultimate bearing capacity of concrete-filled steel tube frames, (3) the four-point support method effectively controlled the wall-plate displacement mode, and (4) the degree of horizontal constraint at the upper support joint connectors significantly affected the wall-plate displacement mode.

Copyright ( $) 2021$ by The Hong Kong Institute of Steel Construction. All rights reserved.

\section{Introduction}

Due to rapid social and economic growth and the implementation of industrialised construction in China, pre-fabricated buildings have been widely constructed. However, pre-fabricated buildings possess certain inherent defects that can have fatal consequences, e.g., weak integrity and poor seismic performance. Investigations following an earthquake revealed that the crumbling and destruction of the building envelope was one of the main causes of deaths and injuries. Therefore, while introducing steel structures, steel-concrete composite structures and other new structures systems into the pre-fabricated buildings, it is also important to conduct research on the seismic behaviour of pre-fabricated structural components such as concrete-filled steel tubes (CFSTs) and sandwich composite wall panels (SCWPs), as well as the envelope structure SCWPs constitute.

The SCWP is composed of two outer reinforced concrete (RC) layers a core insulation layer, and the connectors which linked the two RC layers. These panels do not require a secondary insulation layer structure and have excellent economic, social, and environmental benefits. Hence, SCWPs are expected to become the future building blocks of wall structures. However, further research is needed to study the reliability of the connection between SCWPs and the main structure. To this end, Markulak et al. performed tests on various types of masonry embedded in $\mathrm{H}$-shaped steel frames [1]. Benayoune et al. conducted both experimental and theoretical studies on the structural behaviour of precast concrete sandwich panels under flexural and axial loads [2-4]. Darzi et al. investigated the flexural stiffness and ultimate load capacity of novel ultralight composite sandwich panels made of plywood faces and bamboo or peeling cores [5]. Li and Dong studied the shear-resistance behaviour of a light composite shear wall [6]. Huang and Dai conducted a four-point bending test to investigate the flexural performance of the fiber reinforced polymer (FRP) connector enabled precast geopolymer concrete sandwich panel [7]. Xu and Li described quasi-static tests and simulations of both cast-in-situ and precast concrete sandwich walls [8].

The behaviour of CFST frame components has also been the subject of investigation. Han et al. described the behaviour of CFSTs under axial tension [9]. Moon et al. proposed a simplified model for the bending behaviour of CFSTs [10]. Pagoulatou et al. conducted a finite element analysis and investigated the compression behaviour of circular concretefilled double-skin steel tubes [11]. Lastly, Agheshlui et al. studied the tensile behaviour of groups of Ajax-anchored blind bolts used within square CFST sections [12].

Extensive research has been conducted on the hysteretic behaviour of CFSTs with SCWPs. Wang et al. conducted experiments on CFST frames with external SCWPs and studied the seismic behaviour of blind-bolted CFST frames infilled with precast SCWPs under various parameters [13].
Fang performed shaking-table tests and studied the destruction properties of autoclaved lightweight aerated concrete (ALC) external walls [14]. Ma and Jiang investigated the seismic performance of a new environmentally friendly gypsum-concrete composite interior wallboard and demonstrated its excellent seismic behaviour; they also found that the ductility of the proposed green wallboard was better than that of a conventional steel reinforced concrete wallboard [15]. Tasnimi and Mohebkhah studied the in-plane seismic behaviour of steel frames infilled with clay brick masonry and openings [16]. Hou et al. investigated the seismic behaviour of H-shaped steel frames with embedded lightweight infill wall panels $[17,18]$. Hashemi et al. also conducted cyclic loading tests on steel frame infill walls and explored the influence of the walls on the behaviour of the main structure [19]. Finally, Wang et al. explored the failure modes of and interaction between ALC walls and CFST frames under seismic loading tests [20,21].

The present study considered a wall panel joint utilising a four-point support flexible connection form to connect a precast concrete SCWP to a CFST frame. A pseudo-static test was then performed on the overall CFST frame. Simultaneously, the inter-laminar displacement mode of the external SCWP was analysed during the test, and the influence of the connecting bolt type on the overall seismic performance was studied.

\section{Experimental program}

\subsection{Design of specimens}

The main control parameters of the test included the presence or absence of an external SCWP in the frame, the steel beam span, the SCWP size, the size of the wall opening area, and the bolt type in the upper support joints. Five full-scale, single-floor, single-span frame specimens were designed, of which two were empty frames (KJ1 and KJ3) and three of which were CFST frames with external SCWPs (KJ2, KJ4, and KJ5). The steel used in the test was Q345B. The frame columns were square CFSTs with cross-sectional dimensions of $200 \mathrm{~mm} \times 200 \mathrm{~mm} \times 10 \mathrm{~mm}$, $3100 \mathrm{~mm}$ long, and filled with C30 concrete. The H-section beams were designed with cross-sectional dimensions of $300 \mathrm{~mm} \times 180 \mathrm{~mm} \times 6 \mathrm{~mm}$ $\times 10 \mathrm{~mm}$. The beam-column joints adopted a bolted-welded hybrid connection; in other words, the beam flange was welded to the outer diaphragm of the CFST column, and 10.9-grade M20 high-strength bolts were used to connect the beam web to the column. The thickness of the SCWPs was $150 \mathrm{~mm}$. The core thermal insulation layer was a $50 \mathrm{~mm}$ thick extruded polystyrene board, which was sandwiched between the $50 \mathrm{~mm}$ thick C30 reinforced concrete slabs. The surface layer of the SCWP was embedded with a steel reinforcing mesh of $\Phi 6$ @ 150, and a vertically arranged steel truss was connected to the steel mesh to form a steel mesh reinforcing skeleton. The main connections between the external wall 
panel and the main frame consisted of two upper and two lower connection joints; the lower joints were mainly used for bearing the load and the upper joints were mainly used for reducing the displacement of the wall. The external SCWP was placed vertically on the supporting plate of the lower joints and was connected to all four joints using bolts. Except for the upper joints of $\mathrm{KJ} 4$, which were connected to the bottom flange of the steel beam using ordinary 4.8 -grade bolts, all joints were connected using 10.9-grade M20 high-strength bolts. Details of the test specimens are shown in Fig. 1, and the investigating parameters can be seen in Table 1 .

Table 1

Parameters of test specimens

\begin{tabular}{cccccc}
\hline Specimen & $\begin{array}{c}\text { Beam } \\
\text { length } \\
L\end{array}$ & $\begin{array}{c}\text { Wall size } \\
(\mathrm{mm})\end{array}$ & $\begin{array}{c}\text { Opening } \\
\text { size }(\mathrm{mm})\end{array}$ & $\begin{array}{c}\text { Relative } \\
\text { opening } \\
\text { area }(\%)\end{array}$ & $\begin{array}{c}\text { Upper } \\
\text { joint bolt } \\
\text { type }\end{array}$ \\
\hline KJ1 & 2000 & - & - & - & - \\
KJ2 & 2000 & $1880 \times 2920$ & $600 \times 1500$ & 16.4 & $\begin{array}{c}\text { High- } \\
\text { strength } \\
\text { bolts }\end{array}$ \\
KJ3 & 2800 & - & - & - & $\begin{array}{c}- \\
\text { Ordinary } \\
\text { bJ4 }\end{array}$ \\
& 2800 & $2760 \times 2920$ & $600 \times 1500$ & 11.2 & $\begin{array}{c}\text { High- } \\
\text { strength } \\
\text { bolts }\end{array}$ \\
\hline KJ5 & 2800 & $2760 \times 2920$ & $600 \times 1500$ & 11.2 & \\
\hline
\end{tabular}

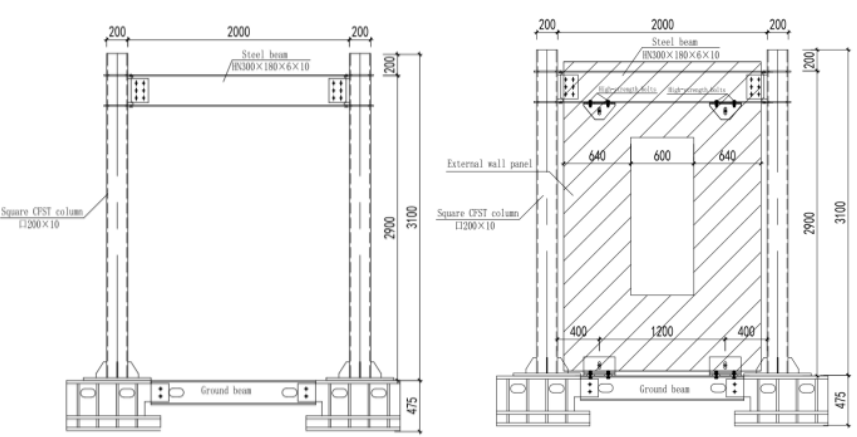

(a) KJ1

(b) $\mathrm{KJ} 2$

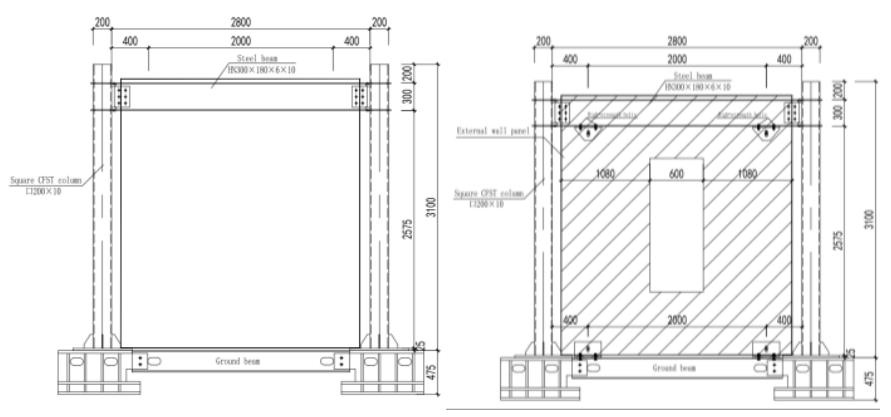

(c) $\mathrm{KJ} 3$

(d) KJ4
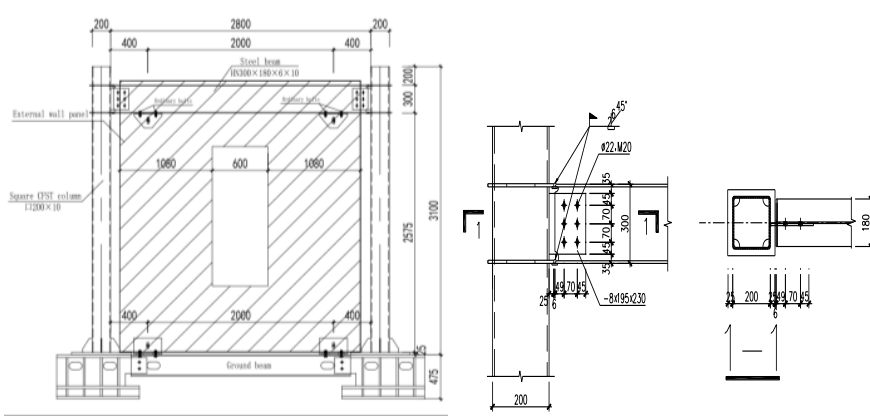

$\Downarrow \ldots$

(e) KJ5

(f) Details of beam-column joints
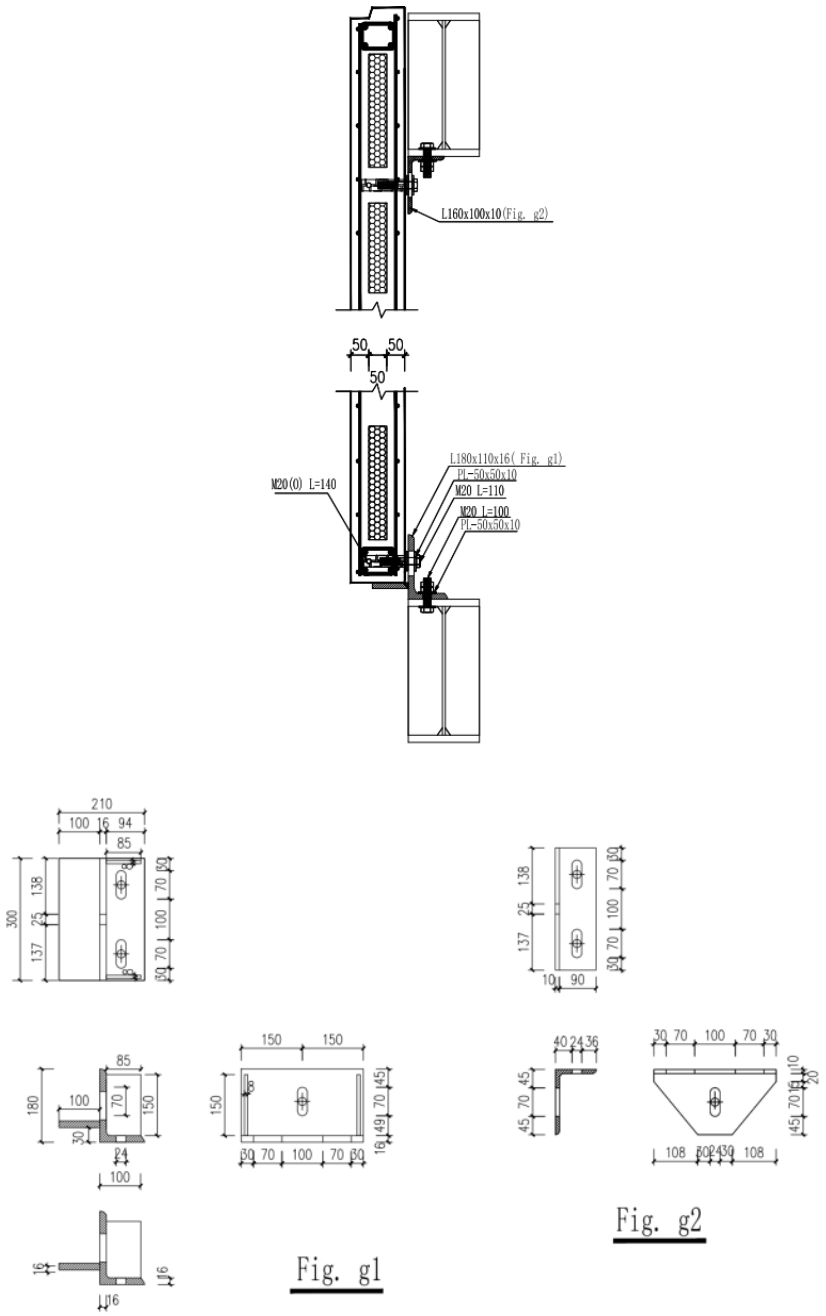

Fig. g2

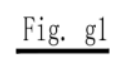

(g) Details of support joint connectors

Fig. 1 Specimen details (units: mm)

\subsection{Cyclic loading apparatus}

A hydraulic servo actuator (MTS, Inc.) was used to perform pseudostatic load to the specimens. One end of the actuator was fixed to a reaction wall, and the other end was connected to the test specimen through a loading head. The column base was connected to a steel pier, and this steel pier was anchored to the ground using anchor rebar. The column was fixed by the ground beam and the hydraulic jack to ensure that the rigid foundation would constrain the bottom of the column. Simultaneously, four constraining pull rods were located on each side of the specimen to ensure the stability of the entire frame during horizontal reciprocating loading. The arrangement of the experimental apparatus is shown in Fig. 2, and images of the test setup are shown in Fig. 3.

Before each specimen was formally loaded, a 5-mm lateral displacement was applied to the specimen by the actuator, then this displacement was reversed to $-5 \mathrm{~mm}$. This cycle was conducted twice to confirm that the loading system and measuring devices were well worked. All specimens were tested under low-cycle horizontal loads in accordance with ATC-24 guidelines [22], as illustrated in Fig. 4. The actuator applied a low-cycle reciprocating lateral displacement to each test specimen at a speed of $0.5 \mathrm{~mm} / \mathrm{s}$. The displacement $\Delta y$ at the yield point was considered as the control displacement ( $\Delta y$ for all the test specimens was $12 \mathrm{~mm}$ ). Before each test specimen yielded, the loading amplitude was controlled at levels of $0.25 \Delta y, 0.5 \Delta y$, and $0.7 \Delta y$, each of which was cycled twice. After the test specimens reached the yield point, loading levels of $1 \Delta y$, $1.5 \Delta y, 2 \Delta y, 3 \Delta y, 5 \Delta y, 7 \Delta y$, and $8 \Delta y$ were applied. The first three levels $(1 \Delta y, 1.5 \Delta y$, and $2 \Delta y)$ were cycled three times, and the remaining levels were cycled twice. 


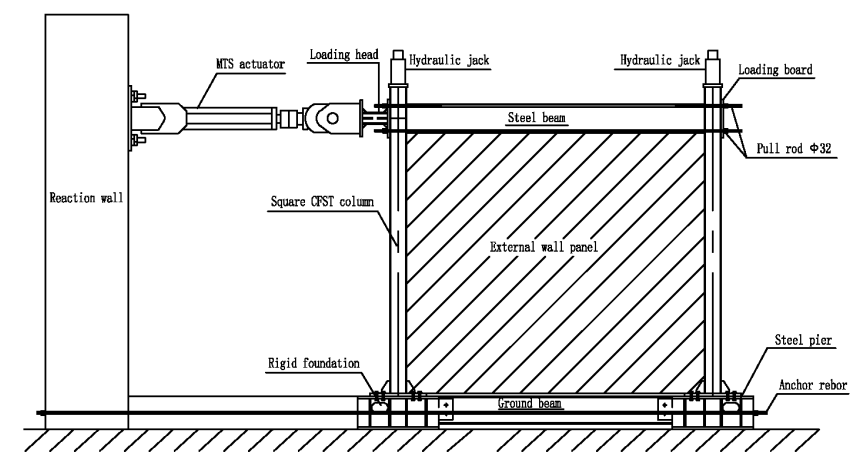

Fig. 2 Experimental setup

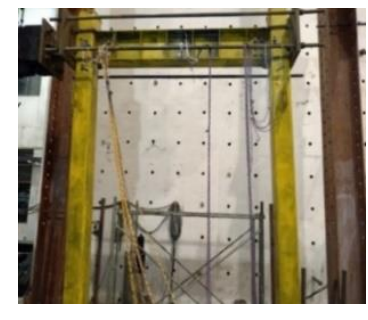

(a) KJ1

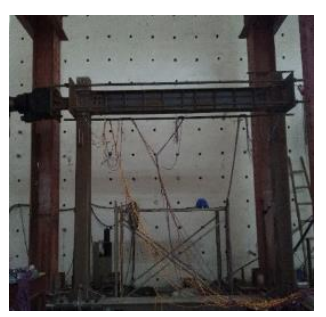

(c) $\mathrm{KJ} 3$

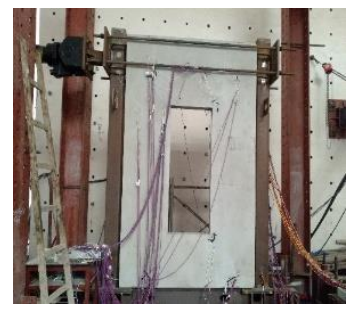

(b) KJ2

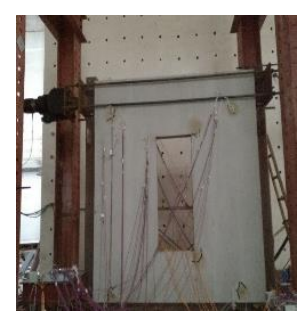

(d) $\mathrm{KJ} 2$

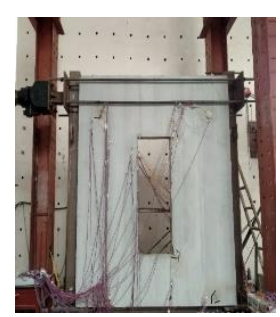

(e) KJ5

Fig. 3 Test setup photographs

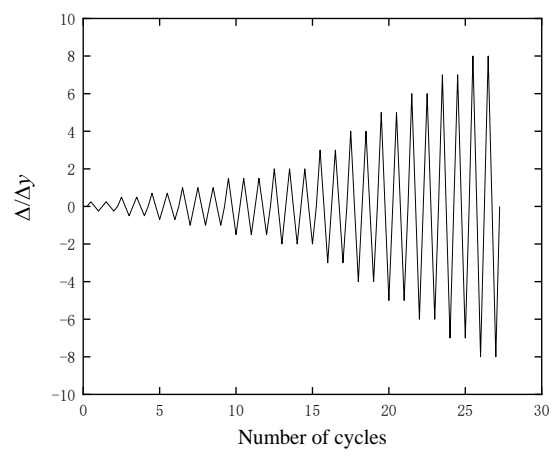

Fig. 4 Loading history

\subsection{Layout of strain gauges}

The following measurement parameters were determined based on the objective of this experimental research:

(1) Load and displacement at the test specimen loading position: During the test, the servo-hydraulic machine automatically collected the horizontal load $(\mathrm{P})$-horizontal displacement $(\Delta)$ data.

(2) Strain in key parts: A multifunctional static strain test system (JM3813) was used to record the strain in the test specimen during the test. Strain gauges were installed on three parts of the specimen: the steel frame, wall panel, and the support joint connectors. The numbers and locations of the strain gauges are shown in Fig. 5.

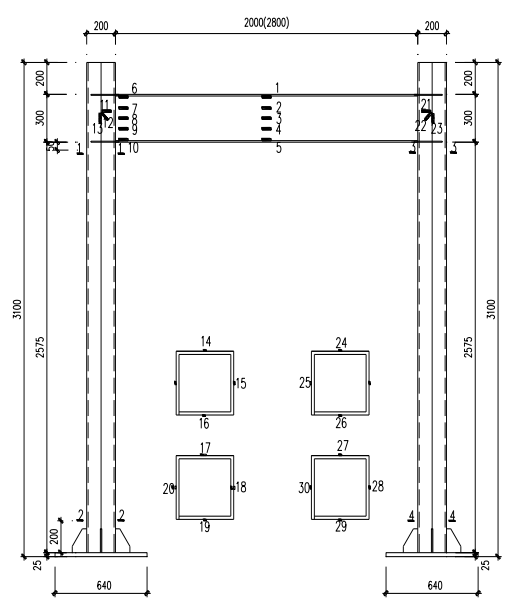

(a) Layout of strain gauges on CFST frame

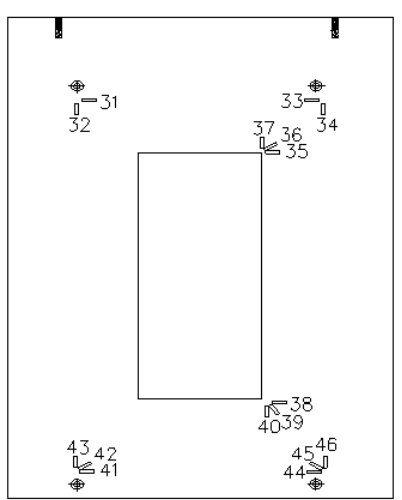

(b) Layout of strain gauges on panels
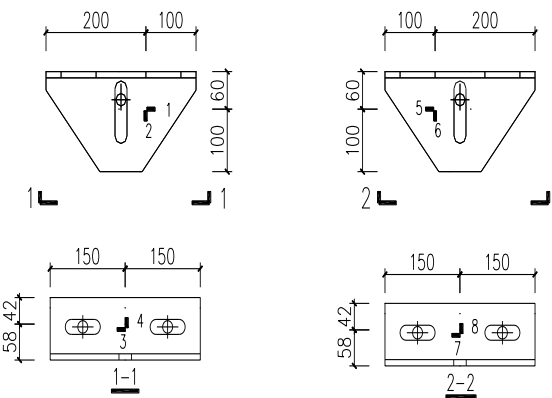

(c) Layout of strain gauges on upper connectors
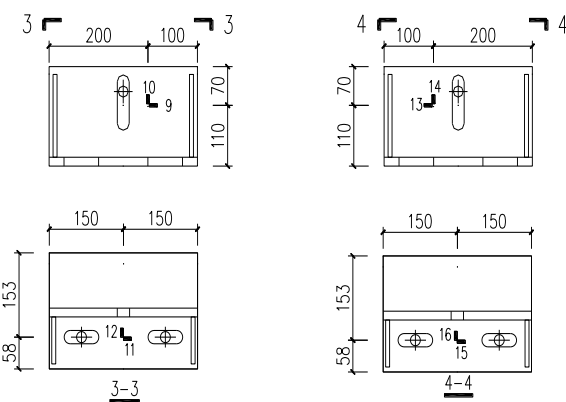

(d) Layout of strain gauges on lower connectors 


\section{Experimental observations}

\subsection{Specimen $K J 1$}

KJ1 was a pure square CFST frame with no SCWP. The specimen exhibited a high level of integrity and ductility as the applied displacement increased. When the column-end displacement reached $60 \mathrm{~mm}$ in the first $5 \Delta y$ cycle, the weld in the bottom flange of the steel beam began to crack. The flanges at both ends of the steel beam were considerably buckled at $96 \mathrm{~mm}$. Furthermore, the weld in the bottom flange at the right end of the steel beam was severely torn. The test was stopped when the bottom flange of the steel beam exhibited weld fracture. The failure mode of specimen $\mathrm{KJ} 1$ is shown in Fig. 6.

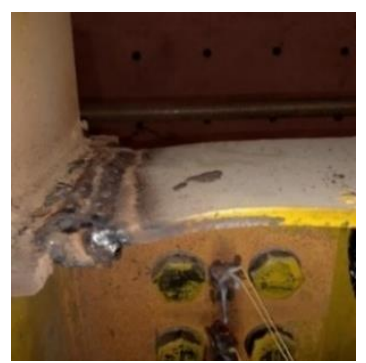

(a) Buckling in top flange

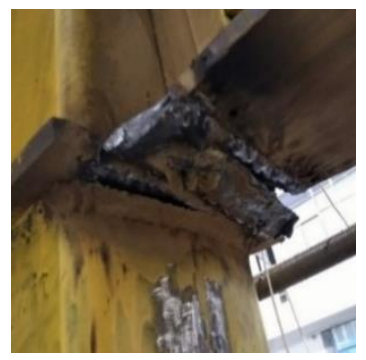

(c) Weld fracture in bottom flange

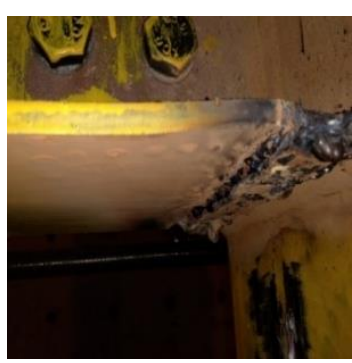

(b) Buckling in bottom flange

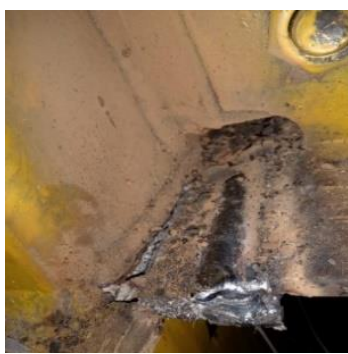

(d) Weld fracture in bottom flange
Fig. 6 Failure modes of beam in specimen KJ

\subsection{Specimen $K J 2$}

KJ2 was a CFST frame with an external SCWP. The specimen was well-stressed in the first and middle stages of the test load, and no apparent yielding or failure occurred. During this period, a faint sound of friction and squeezing of the steel was heard, indicating that a slight slippage of the specimen had occurred. When the displacement reached $60 \mathrm{~mm}$ in the first $5 \Delta y$ cycle, cracks appeared in the panel opening, the top flanges of the steel beam buckled slightly, the lower left corner of the wall panel separated from the lower support joint connector bracket, and the lower left joint bolt slid upwards in its vertically oblong hole. When the columnend displacement reached the first $7 \Delta y$ cycle, the top flanges at both ends of the steel beam buckled considerably; moreover, cracks appeared at the four corners of the wall panel opening and gradually extended towards the joint. The connecting bolt of the lower right joint was cut off at $-62 \mathrm{~mm}$ in the first $7 \Delta y$ cycle, and an instantaneous displacement occurred between the wall panel and the frame. Thereafter, the test was terminated. The failure modes of specimen KJ2 are shown in Fig. 7.

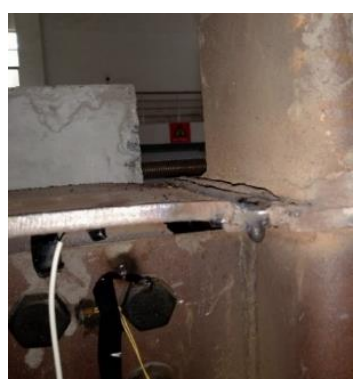

(a) Buckling in top flange

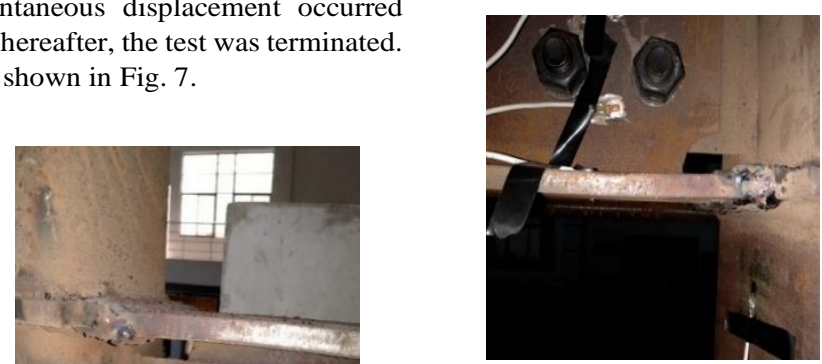

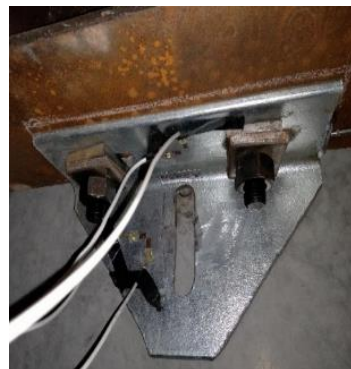

(d) Shearing of bolts

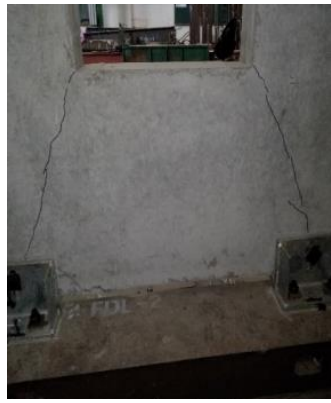

(f) Cracks around panel opening (e) Cracks around panel opening

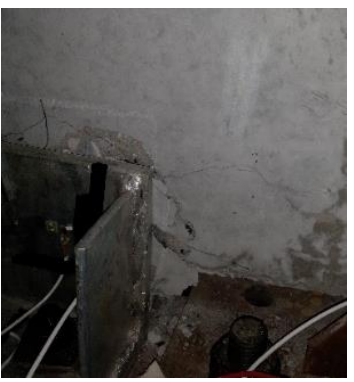

(g) Cracking of concrete around lower connectors

\subsection{Specimen $K J 3$}

KJ3 was a pure square CFST frame. The specimen exhibited good integrity and ductility with the increase of the applied displacement. When the displacement reached $60 \mathrm{~mm}$, the bottom flange at the left end of the steel beam began to buckle, and a slight tearing sound was heard from the weld. Similarly, when the applied displacement reached $-60 \mathrm{~mm}$ in the first $5 \Delta y$ cycle, the top flange at the left end of the steel beam buckled. When the loading reached $84 \mathrm{~mm}$ in the first $7 \Delta y$ cycle, the weld at the bottom flange at the right end of the steel beam was torn. Similarly, when the loading reached $-84 \mathrm{~mm}$ in the first $7 \Delta y$ cycle, the weld in the bottom flange at the left end of the steel beam was torn. After two cycles of $9 \Delta y$ loading, the welds at both ends of the beam were damaged considerably, and severe flange buckling occurred. The loading was then stopped. The failure modes of specimen $\mathrm{KJ} 3$ are shown in Fig. 8. (a) Buckling in bottom flange

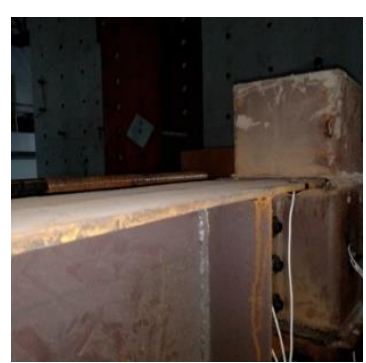

(b) Buckling in top flange 


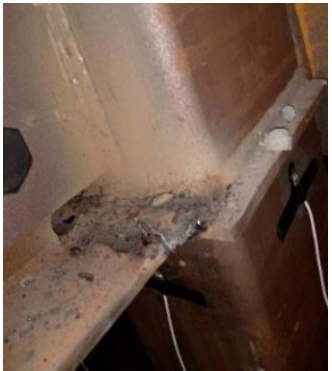

(c) Weld fracture in bottom flange

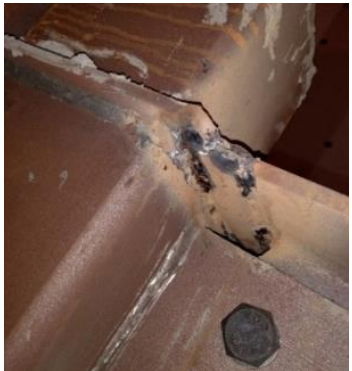

(d) Weld fracture in top flange
Fig. 8 Failure modes of beam in specimen KJ3

\subsection{Specimen KJ4}

KJ4 was a CFST frame with an external SCWP. The test specimen was well-stressed in the first and middle stages of the test load, and no apparent yielding or failure occurred. During this period, a slight sound of friction and squeezing of the steel was heard, indicating that slight slippage of the specimen had occurred. When the loading reached $36 \mathrm{~mm}$ in the first $3 \Delta y$ cycle, the upper support joint bolts slid in their holes, and small cracks developed on the inner face of the wall panel at the corners of the opening. The cracks gradually extended towards the joints and the right end of the wall panel was slightly lifted away from the lower joint plate at $-60 \mathrm{~mm}$. When the applied displacement reached $84 \mathrm{~mm}$ in the first $7 \Delta y$ cycle, oblique cracks appeared on the exterior surface of the wall panel at the four corners of the opening. Cracks appeared in the concrete at the embedded parts of the lower support joints of the wall panel, and the sliding of the bolts in the vertically oblong hole of the lower support joints was restricted. The connecting bolt of the joint was cut off at -78 $\mathrm{mm}$ in the first $7 \Delta y$ cycle, and an instantaneous displacement occurred between the wall panel and the frame. The failure modes of specimen KJ4 are shown in Fig. 9.
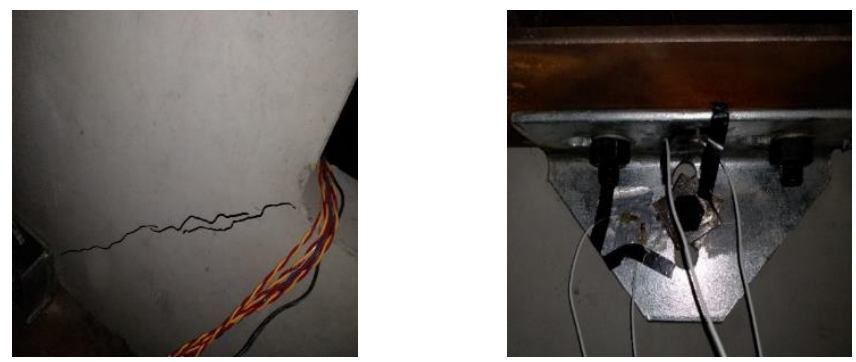

(a) Cracking around panel openings (b) Sliding of upper connector relative to steel beam

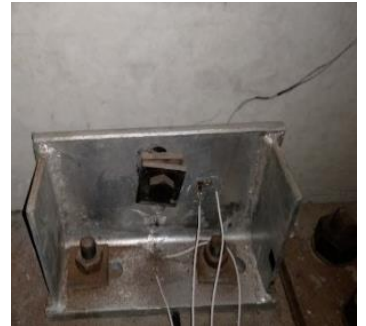

(c) Cracking of concrete around connectors

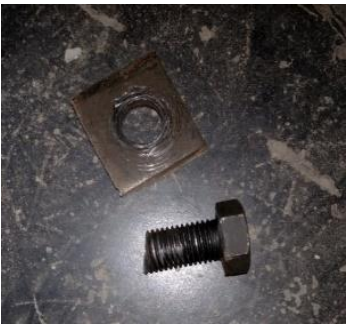

(d) Sheared connector bolt
Fig. 9 Failure modes of specimen KJ4

\subsection{Specimen $K J 5$}

KJ5 was a CFST frame with an external SCWP. The test specimen was well-stressed in the first and middle stages of the test load, and no apparent yielding or failure occurred. During this period, a slight sound of friction and squeezing of the steel was heard, indicating that the specimen had slightly slipped. When the applied displacement reached $60 \mathrm{~mm}$ in the first $5 \Delta y$ cycle, slight cracking occurred on inner surface of the concrete at the upper left and lower right corners of the wall panel opening that gradually extended towards their respective joints, the left end of the wall panel was slightly lifted away from the lower support joint connector, and the lower support joint was vertically elongated. The lower support joint connector bolts accordingly slid upwards, and the wall panel and lower right joint connector plate were squeezed together, cracking the former. Similarly, when the displacement reached $-60 \mathrm{~mm}$, small-scale concrete cracking occurred in the wall that progressively extended towards the joints; moreover, the right end of the wall panel was slightly lifted away from its lower support joint plate. The lower right connector bolt slid upwards in its hole, and the wall panel and the support plate of the lower left joint were squeezed together, cracking the former. When the loading reached $76 \mathrm{~mm}$, the lower right support joint connector bolt was sheared, and an instantaneous displacement occurred between the wall panel and frame. Similarly, when the applied displacement reached -60 $\mathrm{mm}$, the upper support joint connector bolts were sheared, and the panel exhibited an out-of-plane inclination. The failure modes of specimen KJ5 are shown in Fig. 10.

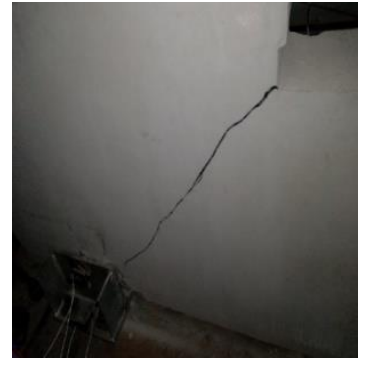

(a) Cracking in panel openings

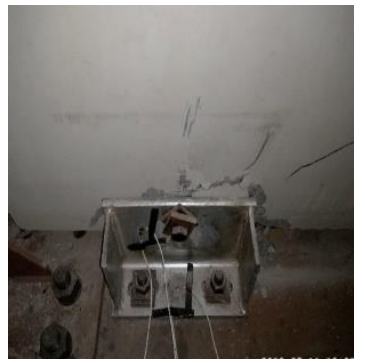

(c) Cracking of concrete at connectors

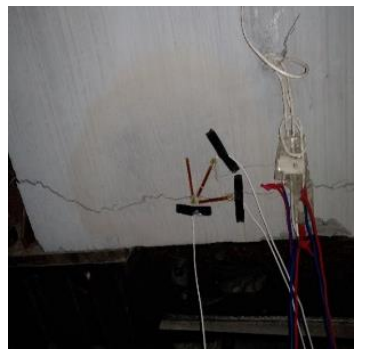

(e) Cracking in wall panel embedded parts

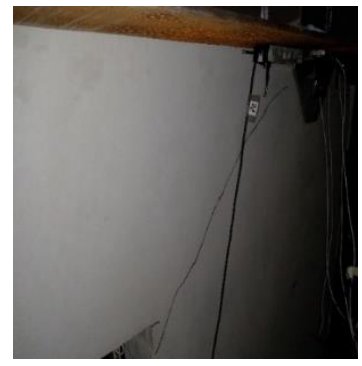

(b) Cracking in panel openings

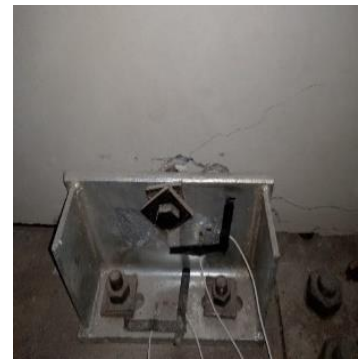

(d) Cracking of concrete at connectors

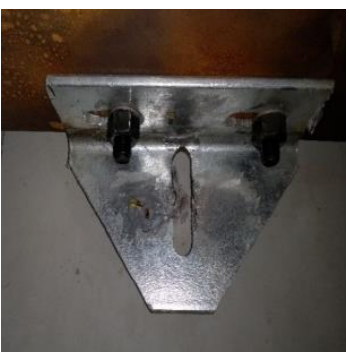

(f) Sheared connector bolt
Fig. 10 Failure modes of specimen KJ5

\section{Analysis of experimental results}

\subsection{Analysis of hysteresis curve}

The measured $\mathrm{P}-\Delta$ hysteresis curve for each specimen is shown in Fig. 11, from which the following conclusions were drawn:

(1) When the displacement magnitude was small in the early part of the test, the loading and unloading curves coincided and passed through the zero point without any reduction in stiffness. The residual deformations of the test specimens were small, and the specimens were in the elastic stage. As the displacement increased, an apparent rheostriction manifested in the curves, reflecting the aforementioned slide in the test. The slopes of the loading curves changed only slightly at this time; however, the slopes of the unloading curves decreased considerably, and the specimens exhibited some residual deformation. The main frames entered the elastoplastic stage; the overall stiffness gradually deteriorated; and the energy dissipation of the specimens gradually increased.

(2) $\mathrm{KJ} 2, \mathrm{KJ} 4$, and $\mathrm{KJ} 5$, which had external SCWPs, exhibited a 
considerably higher initial elastic stiffness than $\mathrm{KJ} 1$ and $\mathrm{KJ} 3$ (without external wall panels), and reached the limit state earlier. The wall panels were damaged before the frames, indicating that the overall structural stiffness of the frames was improved by the SCWPs.

(3) The hysteresis curves of $\mathrm{KJ} 2, \mathrm{KJ} 4$, and $\mathrm{KJ} 5$ all fluctuated considerably in the final loading cycle. Because the connecting bolts between the upper support joint and wall panel were sheared, the wall panel suddenly shifted relative to the frame, causing the sustained load to decrease. This indicates that the upper support joint connector is an essential force-bearing component that affects the ultimate bearing capacity of the entire specimen.

(4) The shear failure of the upper support joint bolts of KJ4 and KJ5 occurred at approximately $7 \Delta y$ and $5 \Delta y$, respectively. The presence of the wall panel was conducive to energy consumption and shock absorption, and delayed the onset of damage to the test specimen. Hence, the seismic performance of the overall structure was improved to a certain extent.

The horizontal $P-\Delta$ envelope curve was plotted for each specimen from the peak load points in each cycle of its hysteresis curve (Fig. 12). Because the obtained envelope curves exhibited no obvious yield point, the universal yield moment method was applied to identify the characteristic values [23], including the yield, limit, and failure points. The method can be explained in detail using Fig. 13. In the figure, the tangent $\mathrm{OH}$ of the skeleton curve passing through the origin $\mathrm{O}$ and the horizontal line of the extreme load point $\mathrm{G}$ intersect at point $\mathrm{H}$. The vertical line passing through $\mathrm{H}$ intersects point $\mathrm{I}$ on the $\mathrm{P}-\Delta$ curve; the line obtained by extending $\mathrm{OI}$ intersects $\mathrm{HG}$ and passes through $\mathrm{H}_{0}$; and the vertical line passing through $\mathrm{H}_{0}$ intersects point $\mathrm{B}$, which is the assumed yield point. Therefore, it was assumed that the descending and ascending sections of the skeleton curve were bilaterally symmetrical about the peak point. When calculating the eigenvalues, the measured points had to be curve-fitted to obtain the skeleton curve model. The characteristic values are shown in Table 2. The specimens with external SCWPs yielded and failed earlier than the empty-frame specimens, and their yield points were closer to the limit point. However, the specimens with external SCWPs exhibited a higher load carrying capacity, indicating that the external SCWPs reduced the overall ductility of the frame while improved the load carrying capacity. At the same column displacement, the load on $\mathrm{KJ} 2$ was higher than that on $\mathrm{KJ} 1$, and the loads on $\mathrm{KJ} 4$ and $\mathrm{KJ} 5$ were higher than that on KJ3. These results demonstrate that the external SCWP improved the overall rigidity of the CFST frame but had negligible effect on its bearing capacity.

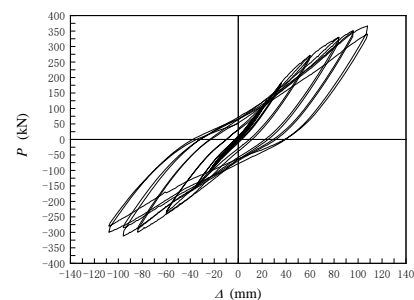

(a) KJ1

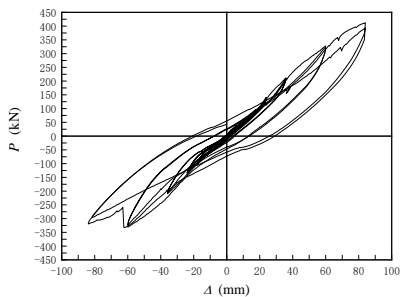

(b) $\mathrm{KJ} 2$

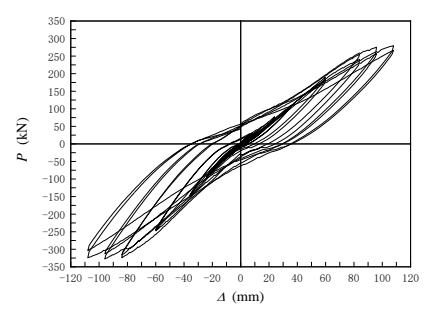

(c) $\mathrm{KJ} 3$

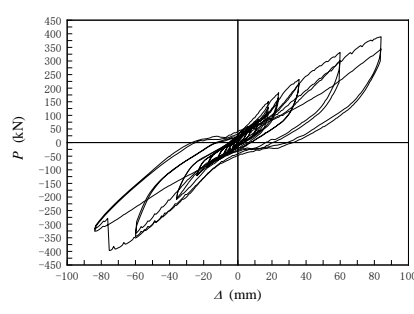

(e) KJ4

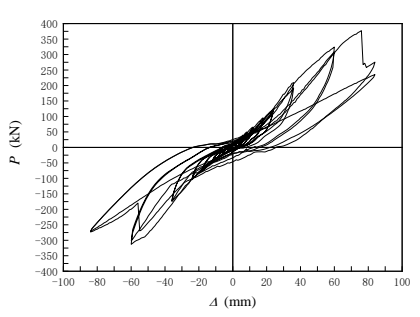

(f) KJ5

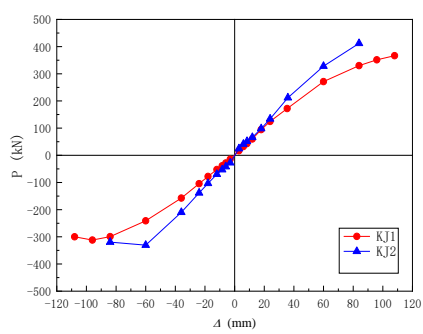

(a) KJ1 and KJ2

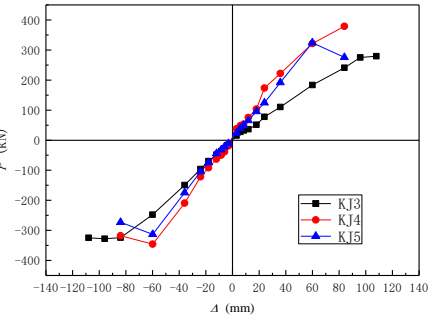

(b) $\mathrm{KJ} 3, \mathrm{KJ} 4$, and $\mathrm{KJ} 5$
Fig. 12 Load $(P)$-displacement $(\Delta)$ envelope curves of specimens

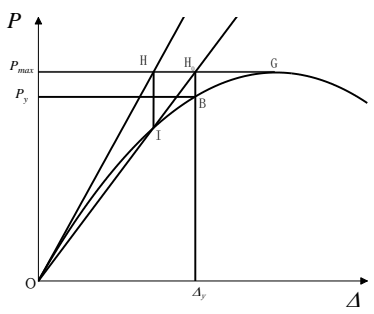

Fig. 13 General yield bending moment method

Table 2

Characteristic values of specimen load-displacement skeleton curves

\begin{tabular}{ccccccc}
\hline & \multicolumn{2}{c}{ Yield point } & \multicolumn{2}{c}{ Limit point } & \multicolumn{2}{c}{ Failure point } \\
Specimen & $\Delta y$ & $P_{y}$ & $\Delta_{\max }$ & $P_{\max }$ & $\Delta u$ & $P_{u}$ \\
& $(\mathrm{~mm})$ & $(\mathrm{kN})$ & $(\mathrm{mm})$ & $(\mathrm{kN})$ & $(\mathrm{mm})$ & $(\mathrm{kN})$ \\
\hline KJ1 (-) & 77.9 & 290.0 & 96.0 & 312.0 & 124.4 & 265.2 \\
$\mathrm{KJ} 2(-)$ & 57.4 & 321.2 & 62.4 & 332.3 & 75.4 & 282.4 \\
$\mathrm{KJ} 3(-)$ & 79.9 & 311.1 & 96.0 & 327.6 & 123.4 & 278.5 \\
$\mathrm{KJ} 4(-)$ & 66.9 & 385.9 & 75.4 & 396.7 & 94.5 & 337.2 \\
$\mathrm{KJ} 5(+)$ & 68.1 & 370.1 & 75.9 & 377.1 & 95.3 & 320.5 \\
\hline
\end{tabular}

\subsection{Strength degradation}

The strength degradation coefficient $\lambda_{i}=F_{j}^{i} / F_{j}^{i-1}$ was used to evaluate the strength degradation of cyclically loaded specimens [24]. Here, $F_{j}^{i}$ is defined as the peak load under the $i$-th loading cycle at the $j$ th loading displacement $(\Delta / \Delta y=j)$, and $F_{j}^{i-1}$ is defined as the peak load under the $i$-1 th loading cycle at the $j$-th loading displacement $(\Delta / \Delta y=j)$. The strength degradation coefficients of each specimen were calculated from the $P-\Delta$ hysteresis curves; the results are shown in Fig. 14. P and $\mathrm{N}$ in the figure represent the loads in positive and negative directions, respectively. Here, no apparent trend of strength degradation could be seen in the elastic stage; however, when the specimens were in the elastoplastic stage, the strength degradation coefficient gradually decreased. The strength degradation coefficients of all specimens were less than 1 in most cases, and the variation range was small; this indicates that the strength degradation of the specimen was small, and the specimen could be stable under the same load at different displacement loading cycles. As long as the wall and frame were not separated, the structure was still able to effectively resist lateral loads. Moreover, in $\mathrm{KJ} 2, \mathrm{KJ} 4$, and $\mathrm{KJ} 5$, the upper joint connector bolts were sheared between $5 \Delta y$ and $7 \Delta y$, and the load carrying capacity was reduced accordingly. However, the coefficient did not decrease significantly at this stage, indicating that the cracks in the wall and even the shear failure of the connecting bolts caused limited strength degradation, and that the specimen structure remained in a relatively stable state. 


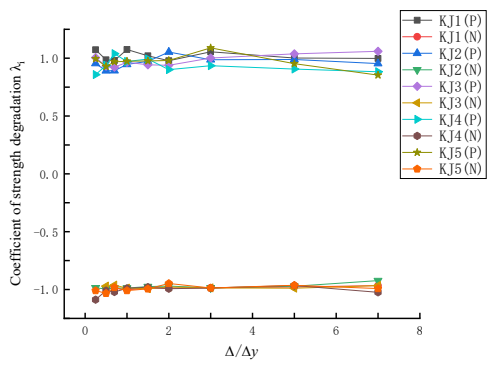

Fig. 14 Coefficient of strength degradation at the same loads

\subsection{Stiffness degradation}

In this study, the Stiffness degradation was discussed based on the secant stiffness. The stiffness degradation coefficient is defined by the following equation:

$K_{i}=\frac{\left|+F_{i}\right|+\left|-F_{i}\right|}{\left|+X_{\mathrm{i}}\right|+\left|-X_{i}\right|}$,

where $+F_{j}$ and $-F_{j}$ are the forward and reverse peak loading values, respectively, and under the $i$-th loading cycle when the horizontal displacement $\left(\Delta / \Delta_{y}\right)$ is equal to $I$, and $+X_{j}$ and $-X_{j}$ are the $i$-th positive and negative peak displacements, respectively.

The stiffness degradation coefficient $K_{i}$ corresponding to loading stage is shown in Fig. 15. The values at the elastic and failure stages were respectively $4.70-5.22$ and $3.09-4.80 \mathrm{kN} / \mathrm{mm}$ for specimen $\mathrm{KJ} 1,5.68$ 8.83 and $4.36-5.86 \mathrm{kN} / \mathrm{mm}$ for specimen $\mathrm{KJ} 2,3.38-5.13$ and $2.80-3.62$ $\mathrm{kN} / \mathrm{mm}$ for specimen $\mathrm{KJ} 3,5.16-7.82$ and $4.09-5.86 \mathrm{kN} / \mathrm{mm}$ for specimen $\mathrm{KJ} 4$, and $5.00-7.70$ and $3.33-5.40 \mathrm{kN} / \mathrm{mm}$ for specimen KJ5. It can be observed in Fig. 15 that the stiffness degradation curve of each specimen roughly follows the same trend: the failure stiffness of the specimen first decreases rapidly, then gradually stabilises, and finally decreases again. A comparison of the stiffness degradation curves of the specimens indicates that the stiffness of the CFST frame was enhanced by the installation of the SCWP.

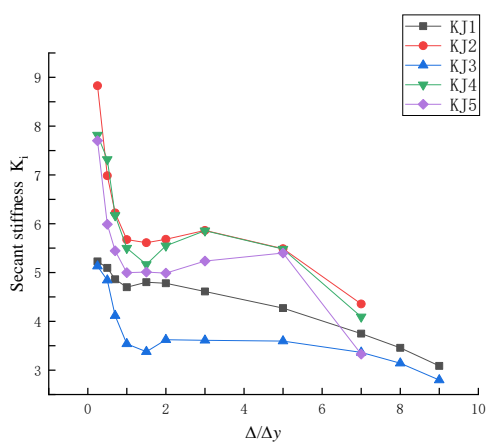

Fig. 15 Relationship between secant stiffness $K_{i}$ and its corresponding loading stage

\subsection{Analysis of load carrying capacity and ductility}

Ductility is an essential characteristic in the seismic design of a structure. It is usually evaluated by the ductility coefficients of the linear and angular displacements. The linear-displacement ductility coefficient $\mu$ is expressed as $\mu=\Delta_{u} / \Delta_{y}$, where $\Delta_{y}$ is the yield displacement and $\Delta_{u}$ is the failure displacement. The angular-displacement ductility coefficient $\mu_{\theta}$ is defined as $\mu_{\theta}=\theta_{u} / \theta_{v}$, where $\theta_{u}=\operatorname{arctg}\left(\Delta_{u} / H\right)$, $\theta_{y}=\operatorname{arct} g\left(\Delta_{y} / H\right)$, and $H$ is the storey height. Here, the failure displacement $\Delta u$ is defined as the displacement corresponding to the failure load $P_{u}=0.85 P_{\max }$. The correlation coefficients of the five specimens were thus calculated and are listed in Table 3.

According to the Code for Seismic Design of Buildings (GB500112010) [25], the limit of the elastic inter-storey horizontal drift angle of a high multi-storey steel structures $\left[\theta_{e}\right]$ is $1 / 250 \approx 4 \mathrm{mrad}$ and the limit of the elastoplastic inter-story horizontal drift angle $\left[\theta_{p}\right]$ is $1 / 50 \approx 20 \mathrm{mrad}$. As seen in Table 2, the determined displacement ductility coefficient is between 1.31 and 1.41, the elastic-limit displacement angle is between 6.08 and 6.19 times $\left[\theta_{e}\right]$, and the elastoplastic-limit displacement angle is between 1.37 and 1.73 times $\left[\theta_{p}\right]$. Thus, the ductility of each specimen was within the limits specified in the aforementioned code and therefore satisfied the seismic requirements.

Table 3

Ductility coefficients of specimens

\begin{tabular}{ccccccc}
\hline Specimen & $\begin{array}{c}\Delta_{y} \\
(\mathrm{~mm})\end{array}$ & $\begin{array}{c}\Delta_{u} \\
(\mathrm{~mm})\end{array}$ & $\begin{array}{c}\theta_{y} \\
(\mathrm{mrad})\end{array}$ & $\begin{array}{c}\theta_{u} \\
(\mathrm{mrad})\end{array}$ & $\mu$ & $\mu_{\theta}$ \\
\hline $\mathrm{KJ} 1$ & 77.9 & 124.4 & 28.32 & 45.21 & 1.60 & 1.60 \\
$\mathrm{KJ} 2$ & 57.4 & 75.4 & 20.87 & 27.41 & 1.31 & 1.31 \\
$\mathrm{KJ} 3$ & 79.9 & 123.4 & 29.05 & 44.84 & 1.54 & 1.54 \\
$\mathrm{KJ} 4$ & 66.9 & 94.5 & 24.32 & 34.35 & 1.41 & 1.41 \\
$\mathrm{KJ} 5$ & 68.1 & 95.3 & 24.76 & 34.64 & 1.40 & 1.40 \\
\hline
\end{tabular}

Note: $\Delta_{y}$ is the yield displacement, $\Delta_{u}$ is the failure displacement, $\theta_{y}$ is the yield displacement angle, $\theta_{u}$ is the failure displacement angle, $\mu$ is the linear-displacement ductility coefficient, and $\mu_{\theta}$ is the angular-displacement ductility coefficient.

\subsection{Dissipated energy}

The energy dissipation capacity is evaluated using the energy dissipation coefficient $E$ or equivalent viscous damping coefficient $\xi_{e}$, which can generally be measured using the area enclosed by the $P-\Delta$ hysteresis curve and calculated by the following formulas:

$\xi_{e}=\frac{1}{2 \pi} \frac{S_{A B C}+S_{C D A}}{S_{O B E}+S_{O D F}}$ and

$E=\frac{S_{A B C}+S_{C D A}}{S_{O B E}+S_{O D F}}=2 \pi \xi_{e}$,

where $S_{A B C}$ and $S_{C D A}$ represent the area of the $\mathrm{ABC}$ and $\mathrm{CDA}$ regions, respectively, and $S_{O B E}$ and $S_{O D F}$ represent the area of the OBE and ODF regions, respectively, of the $P-\Delta$ curve shown in Fig. 16. The equivalent viscous damping curves and cumulative energy consumption curves of the specimens are shown in Fig. 17 and Fig. 18, respectively. Accordingly, the following conclusions were drawn:

(1) The equivalent viscous damping coefficients were both large at the initial stage (before $2 \Delta y$ ) because of slippage and then decreased as the various slippages reached their limits. After $2 \Delta y$, the damping coefficient and energy consumption gradually increased because of the concrete cracking, the buckling of the flanges and web of the steel beam, and the sliding of the bolts in their holes.

(2) In the equivalent viscous damping coefficient graph, the curves for the specimens with external wall panels were higher than those for the empty-frame specimens, indicating that the damage and displacement of the wall panels partly affected the overall energy consumption capacity. The trends of the coefficient curves were similar, and the value of the coefficient of KJ4 was slightly larger than that of KJ5.

(3) The trends of the cumulative energy consumption curves of all specimens were similar. The energy consumption increased slowly before $3 \Delta y$ and then increased rapidly. The stage in which the energy consumption increased rapidly was correlated with the stage in which destruction was observed during the tests. The energy consumption of the CFST frame with external wall panels was considerably greater than that of the empty-frame specimens, and the energy consumption of KJ4 was marginally greater than that of KJ5.

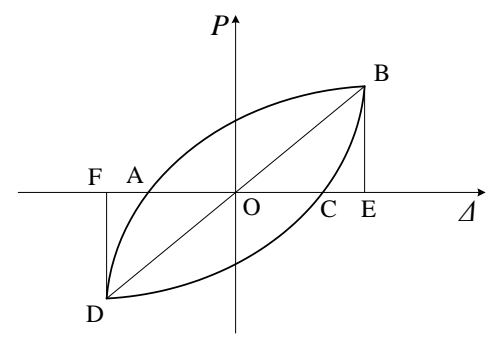

Fig. 16 Hysteresis curve 


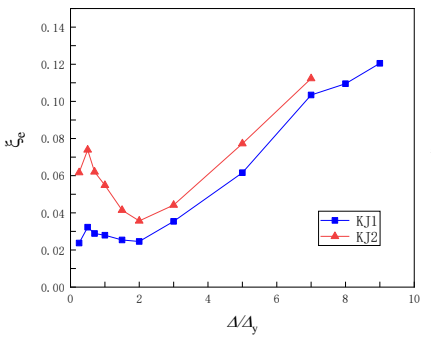

(a) $\mathrm{KJ} 1$ and $\mathrm{KJ} 2$

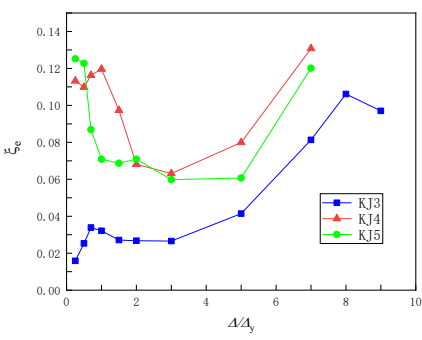

(b) $\mathrm{KJ} 3, \mathrm{KJ} 4$, and $\mathrm{KJ} 5$
Fig. 17 Equivalent viscous damping curves

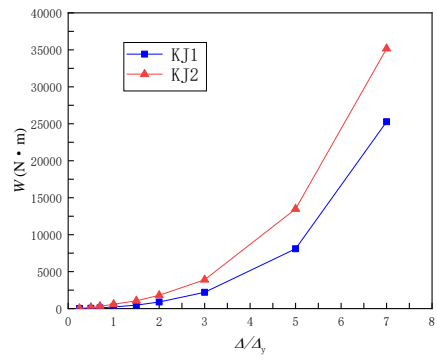

(a) $\mathrm{KJ} 1$ and $\mathrm{KJ} 2$

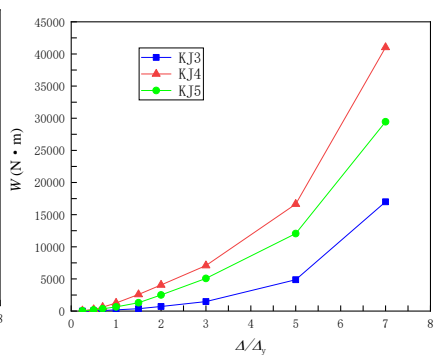

(b) $\mathrm{KJ} 3$, $\mathrm{KJ} 4$, and $\mathrm{KJ} 5$
Fig. 18 Cumulative energy consumption curves

\section{Finite element modelling}

After the quasi-static tests of the five specimens, the seismic performance of each specimen was analysed based on the observed phenomena and obtained data, and corresponding conclusions were drawn. To further investigate the mechanical properties and failure modes of the specimens under low-cycle reciprocating loads, the ABAQUS software was used to conduct non-linear numerical simulation analysis. Thus, ABAQUS finite element models were established based on the actual dimensions of test specimens $\mathrm{KJ} 1$ and $\mathrm{KJ} 2$. These models are shown in Fig. 19.

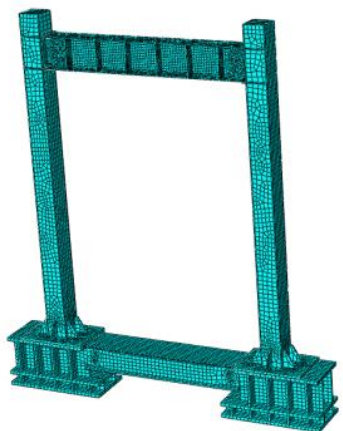

(a) $\mathrm{KJ} 1$

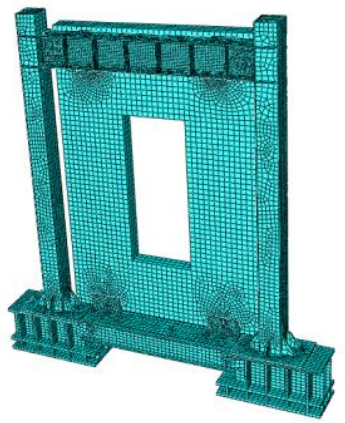

(b) $\mathrm{KJ} 2$
Fig. 19 ABAQUS finite element models

\subsection{Material modelling}

The finite element analyses included two main constitutive models of steel (Fig. 20). One was the secondary plastic flow model that considered five stages: the elastic, elastoplastic, plastic, strengthening, and secondary plasticising stages. The other model was a bi-linear model that considered only the elastic and strengthening stages. In the strengthening stages of bilinear model, the post yield stiffness was taken as $0.01 E s$ (where Es is the elastic modulus of the high-strength steel) [26-28]. The steel beam, steel column, steel pier, ground beam, and joint connection were simulated using the secondary plastic flow model, whereas the high-strength bolt and rebar embedded in the SCWP were simulated using the bi-linear model.

Concrete has different elastoplastic characteristics under tensile and compressive conditions, and a certain degree of loss and damage needs to be considered. Therefore, the concrete model applied in these analyses adopted the concrete constitutive relationship and damage plasticity stipulated in the Code for Design of Concrete Structures (GB50010-2010) [29].

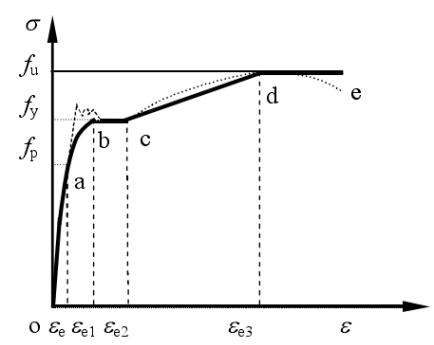

(a) Secondary plastic flow model

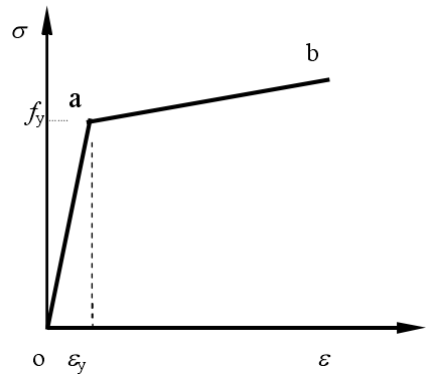

(b) Bi-linear model
Fig. 20 Stress-strain relationship curves of stee

\subsection{Description of finite element model}

The finite element models of $\mathrm{KJ} 1$ and $\mathrm{KJ} 2$ were established according to the actual dimensions of the specimens. The eight-node linear brick continuum element with incompatible modes (C3D8I) was considered to simulate the horizontal deformation of the specimens. The C3D8I elements were used for the concrete, steel beams, ground beams, steel pier, steel columns, bolts, connectors, and other components. Because the reinforcing skeleton was constrained within the wall panel by the embedded area, it was necessary to represent it using linear 3D solid elements and truss elements to replicate the actual stress state. Accordingly, the T3D2 element was used for the reinforcing skeleton in the wall. The mesh partitions are shown in Fig. 21.

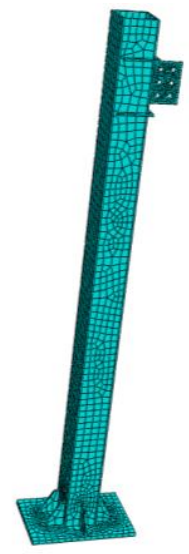

(a) Column

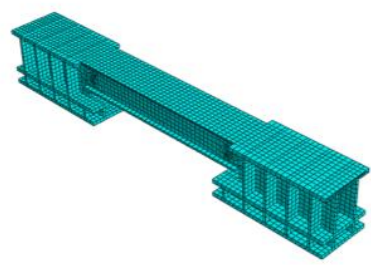

(c) Ground beam

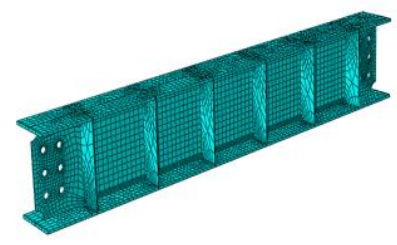

(b) beam

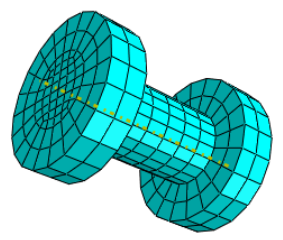

(d) Bolts 


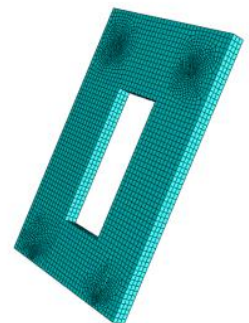

(e) Wall panels

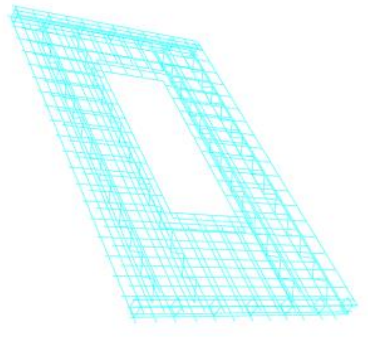

(f) Reinforcing skeleton
Fig. 21 Mesh partitions

The 'Tie' constraint was applied in ABAQUS to simulate the weld between the beam and the outer diaphragm; for example, the weld between the CFST column and the outer diaphragm. The binding constraint was also used between the bolt and its hole in the support joint connector plate because the bolts were firmly connected through this hole throughout the test and the wall panel was not pulled out. The surface-tosurface contact model was adopted to represent the contact between the bolt and specimen, and between the steel beam and support joint connector. The friction formula was set to the 'Penalty' formulation in the tangential direction of the contact pair, and the friction coefficient was set to 0.45 . The constraint between the reinforcing skeleton and wall panel, which both experience the same displacement and deformation, adopted the embedded form. The reinforcing skeleton was considered the embedded area, and the wall panel was considered the main area. To facilitate the loading of the specimen model, the loading surface was coupled to a reference point. This coupling was kinematic, and the constrained area was fully bound to the reference point in all six degrees of freedom. This made the constrained area rigid, and thus only the reference point had to be loaded when a load was applied.

To ensure the complete fixation of the column base, the displacement and rotation were constrained in all six degrees of freedom. The applied loads mainly consisted of:

(1) The pre-tension force applied to the high-strength bolts. According to the Technical Specification for High-Strength Bolt Connections of Steel Structures (JGJ 82-2011) [30], the pre-tension force of the 10.9grade M20 high-strength bolt should be $155 \mathrm{kN}$; therefore, a $155-\mathrm{kN}$ bolt load was applied to the middle surface of the bolt.

(2) The horizontal reciprocating displacement load. The same displacement load used in the actual loading system was applied to the reference point coupled to the loading surface. The cycle period was set according to the displacement amplitude.

\subsection{Validation of the finite element model}

To verify the accuracy of the finite element simulation, the Von-Mises stress contour and their associated experimental phenomena were selected for comparison at various key parts of the specimen, as shown in Fig. 22. The stress characteristics and failure modes obtained from the simulation, including the tearing of the welds, buckling of the steel beam flanges, cracking around the wall openings, and shearing of the support joint connector bolts, were essentially consistent with those obtained from the tests. Compared with the test results, the simulation results indicated greater stiffness, but the ultimate bearing capacities in the two sets of results were similar. This difference was due to the occurrence of various slip phenomena during the physical loading process of the test specimens, whereas it was assumed that no slipping occurred between the frame and SCWP in the finite-element models. A parametric analysis conducted using the finite element simulation indicated that the main factors influencing the seismic performance of the overall frame were the strength of the steel and the relative size of the wall openings in the SCWPs. The strength of the steel considerably improved the ultimate bearing capacity of the structure, but its influence on the elastic stiffness was minor. However, the relative size of the wall openings had a clear effect on both the ultimate bearing capacity and elastic stiffness of the overall structure.
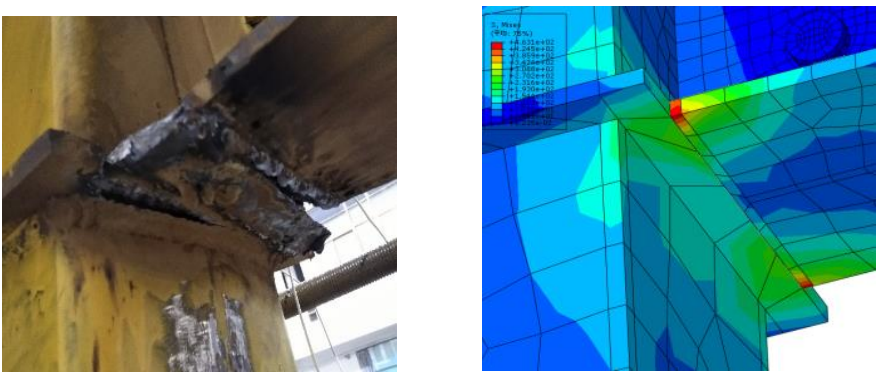

(a) Weld fracture in bottom flange
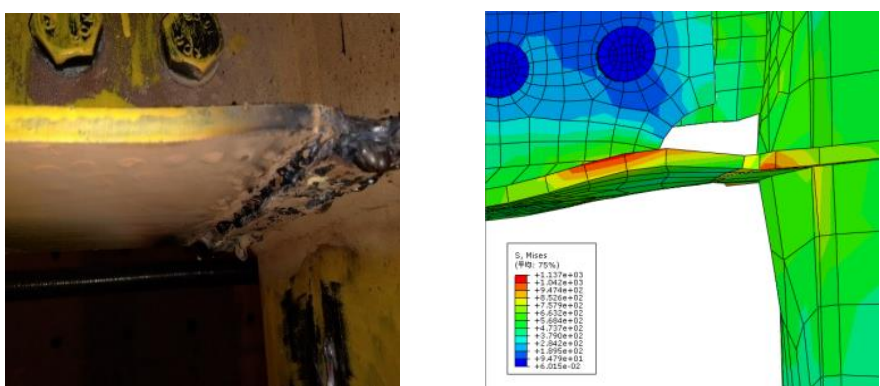

(b) Buckling in bottom flange of beam
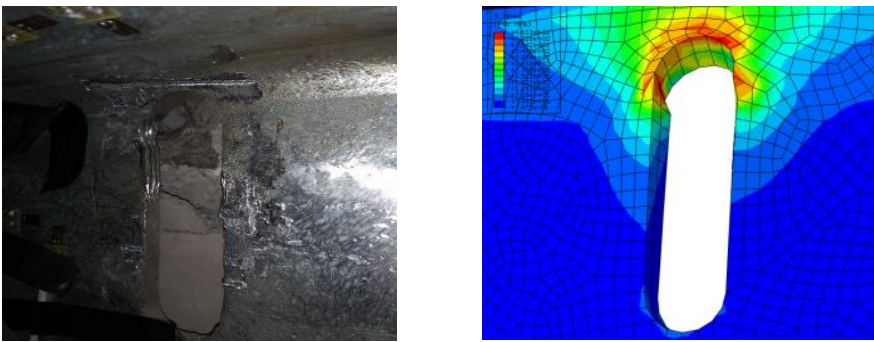

(c) Failure at upper joint connector

Fig. 22 Failure modes and stress contour

\section{Conclusions}

In this study, the seismic performance of CFST frames with external SCWPs was investigated by quasi-static tests, nonlinear finite element simulation, and theoretical analysis. Following conclusions can be drawn based on the conducted investigations:

(1) The failure modes of CFST frames with external SCWPs mainly consist of concrete cracking around the wall openings (which extended towards the joints), concrete cracking at the lower support joints, buckling of the flanges and webs of the steel beams, and weld tearing at the beamcolumn joints. The high-strength bolts of the upper joint connectors first underwent tearing and breaking, and were then sheared, causing the bearing capacity of the structure to decrease.

(2) The CFST frames with external SCWPs exhibited high ductility and good seismic behaviour. The displacement ductility coefficient is between 1.31 and 1.41 ; the elastic-limit displacement angle is between 6.08 and 6.19 times $\left[\theta_{e}\right]$, and the elastoplastic-limit displacement angle is between 1.37 and 1.73 times $\left[\theta_{p}\right]$. The external composite wall panels functioned together with the main frame to resist seismic loads through the joint connections, thereby reducing the damage to the main frame. Simultaneously, the external SCWPs also improved the elastic stiffness and ultimate bearing capacity of the CFST frame. For a single frame, the external SCWP increased the initial elastic stiffness by approximately 40 $50 \%$ and the ultimate bearing capacity by approximately $15-20 \%$. Furthermore, it was discovered that the degree of horizontal constraint at the upper joint connectors had a significant effect on the SCWP displacement mode.

(3) The non-linear finite element analysis effectively simulated the mechanical properties, failure mode, and seismic performance of the test specimens. Thus, the analysis was determined to be accurate and valid. The analysis method and results can serve as a reference for similar engineering applications. A parametric analysis subsequently conducted using the finite element simulation demonstrated that the main influences on the seismic performance of the overall frame were the strength of the steel and the relative size of the wall openings. 
(4) The experiments and theoretical analyses reported herein were conducted for a single storey frame. In actual conditions, the interaction between different storeys and spans will also affect the overall seismic performance and the displacement between the walls. It is therefore important to study wall structures considering multiple stories and multiple spans to obtain more realistic results.

\section{References}

[1] Markulak D., Radić I. and Sigmund V., "Cyclic testing of single bay steel frames with various types of masonry infill", Engineering Structures, 51, 267-277, 2013.

[2] Benayoune A., Samad A.A., Trikha D.N., Ali A.A. and Ellinna S.H.M., "Flexural behaviour of precast concrete sandwich composite panel-Experimental and theoretical investigations", Construction and Building Materials, 22(4), 580-592, 2008.

[3] Benayoune A., Samad A.A.A., Trikha D.N., Ali A.A.A. and Ashrabov A.A., "Structural behaviour of eccentrically loaded precast sandwich panels", Construction and Building Materials, 20(9), 713-724, 2006.

[4] Benayoune A., Samad A.A., Ali A.A. and Trikha D.N., "Response of precast reinforced composite sandwich panels to axial loading", Construction and Building Materials, 21(3), 677-685, 2007.

[5] Darzi S., Karampour H., Gilbert B.P. and Bailleres H., "Numerical study on the flexural capacity of ultra-light composite timber sandwich panels", Composites Part B: Engineering, $155,212-224,2018$

[6] Li S.C. and Dong Y.L., "Shear-resistant behavior of light composite shear wall", Journal of Central South University, 22(7), 2768-2775, 2015

[7] Huang J.Q. and Dai J.G., "Flexural performance of precast geopolymer concrete sandwich panel enabled by FRP connector", Composite Structures, 280, 112563, 2020.

[8] Xu G. and Li A., "Seismic performance of a new type precast concrete sandwich wall based on experimental and numerical investigation", Soil Dynamics and Earthquake Engineering, $122,116-131,2019$

[9] Han L.H., He S.H. and Liao F.Y., "Performance and calculations of concrete filled steel tubes (CFST) under axial tension", Journal of Constructional Steel Research, 67(11), 1699-1709, 2011.

[10] Moon J., Roeder C.W., Lehman D.E. and Lee H.E., "Analytical modeling of bending of circular concrete-filled steel tubes", Engineering Structures, 42, 349-361, 2012.

[11] Pagoulatou M., Sheehan T., Dai X.H. and Lam D., "Finite element analysis on the capacity of circular concrete-filled double-skin steel tubular (CFDST) stub columns", Engineering Structures, 72, pp.102-112, 2014.

[12] Agheshlui H., Goldsworthy H., Gad E. and Yao H., "Tensile behavior of groups of anchored blind bolts within concrete-filled steel square hollow sections", Journal of Structural Engineering, 142(2), 04015125, 2016
[13] Wang J., Li B. and Li J., "Experimental and analytical investigation of semi-rigid CFST frames with external SCWPs", Journal of Constructional Steel Research, 128, 289-304, 2017.

[14] Fang M.J., "Seismic behavior study of external wall panels in steel frames", Advanced Materials Research, 243, 1425-1428, 2011.

[15] Ma S. and Jiang N., "Experimental investigation on the seismic behavior of a new-type composite interior wallboard", Materials and Structures, 49(12), 5085-5095, 2016.

[16] Tasnimi A.A. and Mohebkhah A., "Investigation on the behavior of brick-infilled steel frames with openings, experimental and analytical approaches", Engineering Structures, 33(3), 968980, 2011.

[17] Hou H., Chou C.C., Zhou J., Wu M., Qu B., Ye H., Liu H. and Li J., "Cyclic tests of steel frames with composite lightweight infill walls", Earthquakes and Structures, 10(1), 163-178, 2016.

[18] Hou H., Qiu C., Wang J. and Li G., "An experimental study on sandwich composite panel infilled steel frames", International Journal of Advanced Steel Construction, 8(3), 226-241, 2012.

[19] Hashemi S.J., Razzaghi J., Moghadam A.S. and Lourenço P.B., "Cyclic testing of steel frames infilled with concrete sandwich panels", Archives of Civil and Mechanical Engineering, 18, 557-572, 2018.

[20] Wang B., Wang J., Gong X. and Liu B., "Experimental studies on circular CFST frames with ALC walls under cyclic loadings", International Journal of Steel Structures, 14(4), 755-768, 2014.

[21] Wang J. and Li B., "Cyclic testing of square CFST frames with ALC panel or block walls", Journal of Constructional Steel Research, 130, 264-279, 2017.

[22] ATC-24, Guidelines for Cyclic Seismic Testing of Components of Steel Structures, Applied Technology Council, Redwood City (CA), 1992.

[23] Yao Q., Civil Engineering Structure Testing, Architecture Industrial Press of China, Beijing, 2001 (in Chinese).

[24] JGJ/T 101-2015, Specification for Seismic Testing of Buildings, Architecture Industrial Press of China, Beijing, 2015 (in Chinese)

[25] GB50011-2010, Code for Seismic Design of Buildings, Architecture Industrial Press of China, Beijing, 2010 (in Chinese)

[26] Southeast University, Tianjin University and Tongji University, Principles of Concrete Structural Design, China Architecture \& Building Press, Beijing, 2016 (in Chinese).

[27] Bruneau M., Uang C.M. and Sabelli S.R., Ductile Design of Steel Structures. McGraw Hil Professional, 2011

[28] Wang J., Shen Q. and Li B., "Seismic behavior investigation on blind bolted CFST frames with precast SCWPs", International Journal of Steel Structures, 18(5), 1666-1683, 2018.

[29] GB50010-2010, Code for Design of Concrete Structures, Architecture Industrial Press of China, Beijing, 2010 (in Chinese)

[30] JGJ 82-2011, Technical Specification for High Strength Bolt Connections of Steel Structures, Architecture Industrial Press of China, Beijing, 2011 (in Chinese). 